\title{
Electrolyte imbalances in the aqueous humour in retinoblastoma
}

\author{
P L R DIAS
}

From the Department of Physiology, Faculty of Medicine, University of Colombo, Colombo 8, Sri Lanka

SUMMARY The sodium and potassium concentrations and the lactic dehydrogenase (LDH) activity were estimated in the aqueous and serum of five children with retinoblastoma. Two patients who had a high aqueous LDH activity also showed grossly elevated potassium levels in their aqueous. Though the exact reason for this high potassium concentration in the aqueous is not apparent, it seems likely that cell necrosis within the tumour mass was a contributory factor. It is unlikely that aqueous electrolyte estimations in retinoblastoma could prove to be of any diagnostic value.

The fact that malignant cells in a retinoblastoma secrete various enzymes which by forward diffusion pass into the aqueous and reach significantly higher concentrations in the aqueous than in the plasma was demonstrated by Dias et al.' This aqueous plasma imbalance has been confirmed by several other workers $^{2-6}$ and is of diagnostic significance.

It is also likely that electrolytes, notably potassium, may accompany these enzymes out of malignant cells into the aqueous. As there is no reference in the available literature regarding the electrolyte concentrations in the aqueous in patients with retinoblastoma, it was decided to determine whether electrolyte imbalances do occur between the aqueous and plasma and if so whether these could be of diagnostic value in retinoblastoma.

\section{Materials and methods}

Aqueous humour was collected by aqueous puncture from five children coming up for enucleation for clinically diagnosed retinoblastoma at the Victoria Memorial.Eye Hospital, Colombo. The aqueous was collected while the patient was under general anaes- thesia just prior to enucleation, and great care was exercised to see that none of the specimens was contaminated with blood. Five $\mathrm{ml}$ of blood was also removed from the median cubital vein for biochemical investigations. The sodium and potassium concentrations and the lactic dehydrogenase (LDH) activity in the aqueous and plasma were estimated within four hours of collection of the samples.

Sodium and potassium concentrations were measured by flame photometry after 1 in 100 dilution. LDH activity was estimated by the colorimetric method of King,? in which the increase in optical density at $340 \mathrm{~nm}$ was measured. A unit of activity is the amount of $\mathrm{LDH}$ which reduces $1 \mu$ mole lactate to $1 \mu$ mole pyruvate in 15 minutes at $37^{\circ} \mathrm{C}$. Activity is expressed in units per dl (SI conversion: units/l= units/dl $\times 10$ ).

\section{Results}

The electrolyte concentrations and LDH activity in the aqueous and serum in the five patients with retinoblastoma are shown in Table 1. The LDH aqueous/serum ratio was raised in all specimens. A

Table 1 Electrolyte concentrations and LDH activity in aqueous and serum in five patients with retinoblastoma

\begin{tabular}{|c|c|c|c|c|c|c|c|}
\hline \multirow[t]{2}{*}{ Age } & \multirow[t]{2}{*}{ Sex } & \multicolumn{3}{|c|}{ Aqueous humour } & \multicolumn{3}{|l|}{ Serum } \\
\hline & & $\begin{array}{l}\mathrm{Na} \\
(\mathrm{mmol} / 1)\end{array}$ & $K$ & $\begin{array}{l}\text { LDH } \\
\text { Units }\end{array}$ & $\begin{array}{l}N a \\
(\mathrm{mmol} / 1)\end{array}$ & $K$ & $\begin{array}{l}\text { LDH } \\
\text { Units }\end{array}$ \\
\hline 9 months & $\mathbf{M}$ & 170 & $64 \cdot 1$ & 7000 & 148 & $4 \cdot 8$ & 160 \\
\hline 1 yr 3 months & $\mathbf{M}$ & 136 & $4 \cdot 5$ & 3450 & 140 & $4 \cdot 6$ & 90 \\
\hline 1 yr 8 months & $\mathbf{M}$ & 170 & $5 \cdot 6$ & 1660 & 148 & 3.9 & 310 \\
\hline 11 months & $\mathbf{M}$ & 164 & $39 \cdot 5$ & 4280 & 146 & $4 \cdot 2$ & 195 \\
\hline
\end{tabular}


significant finding was a grossly raised aqueous potassium concentration in two of the specimens.

Subsequent histological examination of the enucleated eyes confirmed the presence of retinoblastoma, and all specimens showed areas of necrosis and calcification. Apart from this there was nothing else of any histological significance in any of the specimens.

\section{Discussion}

The reason for this electrolyte anomaly in the aqueous is not clear. Potassium is known to be secreted by the ciliary processes into the aqueous. In patients with retinoblastoma the intraocular tension is high, and it is likely that the ciliary body is compressed, and the ciliary secretion would, if anything, be reduced.

A differential drainage mechanism for potassium which is altered in some way in retinoblastoma is also possible. If this were so, then all patients with retinoblastoma should show an abnormal increase of potassium in their aqueous.

A potassium concentration of $64.1 \mathrm{mmol} / 1$ was detected in the child who had an aqueous humour LDH activity of $7000 \mathrm{U}$, which was the highest LDH activity recorded in this laboratory. The second child who had a high potassium concentration of 39.5 $\mathrm{mmol} / 1$ also showed a very high LDH activity in the aqueous, but there appeared to be no correlation between the aqueous potassium concentration and the LDH activity in the other specimens.

Possibly a high LDH activity is associated with greater necrosis of the tumour mass, ${ }^{8}$ and this could be the reason for the increased potassium concentration in the aqueous. Necrotic cells probably release their intracellular potassium, which diffuses through the vitreous into the aqueous, but it is difficult to understand why an increase in potassium was not observed in all specimens.

A histological survey of the specimens failed to show a correlation between the extent of necrosis and the potassium concentration in the aqueous.

It is difficult to pinpoint the reason for the significant increase of the potassium concentration in the aqueous in these two patients, and, though unlikely to be of diagnostic significance, it could be of pathophysiological significance. It is intended to perform electrolyte estimations on a much larger sample to determine the cause of the raised potassium concentration in the aqueous humour in patients with retinoblastoma.

I thank the University of Colombo for financial support and Mrs V S B C Fernando for secretarial assistance.

References

1 Dias PLR, Shanmuganathan SS, Rajaratnam M. Lactic dehydrogenase activity of aqueous humour in retinoblastoma. $\mathrm{Br} J$ Ophthalmol 1971; 55: 130-2.

2 Felberg NT, McFall R, Shields JA. Aqueous humour enzyme patterns in retinoblastoma. Invest Ophthalmol Visual Sci 1977; 16: 1039-46.

3 Kabak J, Romano PE. Aqueous humour lactic dehydrogenase isoenzymes in retinoblastoma. Br J Ophthalmol 1975; 59: 268-9.

4 Kaneko A, Suzuki H. Lactic dehydrogenase activity and isoenzymes in retinoblastoma. Nippon Ganka Gakkai Zasshi 1972; 76: 672-5.

5 Swartz M, Herbst RW, Goldberg MF. Aqueous humour lactic acid dehydrogenase in retinoblastoma. Am J Ophthalmol 1974; 78: 612-7.

6 Aksu G. Aqueous humour lactic dehydrogenase activity in normal and diseased eyes. Ann Ophthalmol 1981; 13: 1067-8.

7 King J. A routine method for the estimation of lactic dehydrogenase activity. J Med Lab Technol 1959; 16: 265-72.

8 Dias PLR. Correlation of aqueous humour lactic acid dehydrogenase activity with intraocular pathology. Br J Ophthalmol 1979; 63: 574-7. 